\title{
Experiment Investigation on Fretting Wear and Wear Debris Performance for the Stem-Cement Interface
}

\author{
Lanfeng Zhang, ${ }^{1}$ Shirong Ge, ${ }^{1}$ and Hongtao Liu ${ }^{2}$ \\ ${ }^{1}$ School of Mechatronic Engineering, China University of Mining and Technology, Xuzhou 221116, China \\ ${ }^{2}$ School of Material Science and Engineering, China University of Mining and Technology, Xuzhou 221116, China \\ Correspondence should be addressed to Lanfeng Zhang; lanfeng_zhang8888@126.com
}

Received 7 August 2014; Accepted 27 August 2014

Academic Editor: Tifeng Jiao

Copyright (C) 2015 Lanfeng Zhang et al. This is an open access article distributed under the Creative Commons Attribution License, which permits unrestricted use, distribution, and reproduction in any medium, provided the original work is properly cited.

After the interface debonding, the body protein fluid is subsequently pumped into stem-cement fretting wear interface, serving as the lubricant. On the stem surface, whether there is the influence of protein absorption on fretting wear or not is considered in this study. The biotribological properties at the stem-cement interface were investigated by SEM. The result of hysteresis loops shows that elasticity and plasticity performance of the frictional interface materials can be damaged by fretting fatigue and material energy dissipation will increase periodically. The wear quantity of cement is mainly influenced by load and displacement. The maximum wear loss of bone cement could reach $1.997 \mathrm{mg}$. Bone cement and titanium alloy wear debris, whose size distributions are widely spread from 1 to $110 \mu \mathrm{m}$ and 5 to $150 \mu \mathrm{m}$, respectively, are shaped like tuber, tear, sheet, strip, and sphere, which will induce the osteocyte damage.

\section{Introduction}

The failure of cement type total hip replacement (THR) is mainly due to loose interface caused by different modulus of elasticity of contact materials and the patients' debris disease caused by the continuous friction and wear between components' interfaces [1-3]. Though scholars differ greatly in the complicated causes for the loosening and wear after THR, they have widely accepted the continuous fretting wear at the bone cement-stem interface [4]. The results of Jasty and Zhang showed that the stem-bone cement interface has been cited as a weak link, and it has been indicated from clinical and experimental studies that debonding of this interface may be inevitable $[5,6]$. Lennon and Prendergast and Goodman demonstrated that the bone cement solidifying technology, human body environment, and the mechanical fretting of bone cement-stem interface work together, which make the influence process of interfacing wears more complicated [7, 8]. In addition, impacted by the tiny interface and metal shadow, it is hard to inspect whether there are fretting wears on interface through X-ray and CT scanning which has been verified by Ryd et al., whereas the stem's sinking distance, interface's normal load, and microdislocation can damage the elastic-plastic characteristics of replacement components on one hand [9-11] and induce the growth of fibrous tissue and the appearance of wear debris on interface, which initiate aseptic inflammation finally $[12,13]$. Therefore, it is urgent to make analysis on fretting wear characteristics of bone cement-stem interface.

Earlier researchers mainly conducted with mechanical fixation and the implantation of prosthesis [14-16], which will induce fretting fatigue and then fretting wear. Later on, researchers discovered that fretting wear is related not only to fatigue but also to environment [15-19], let alone studying the fatigue damage process of implant material through the hysteresis loops, which was complemented by this paper. Accordingly, numerous researches of Geringer et al. focused on the effects of serum on fretting wear interface and found that without albumin the interface wear quantity of concave and convex points increase as the chloride converges, whereas protein not only can protect the interface from being worn but prevent erosion [20-24]. Being influenced by the electrochemistry of the body, Kim et al. find that chloride can increase the quantity of concave and convex points in wear 


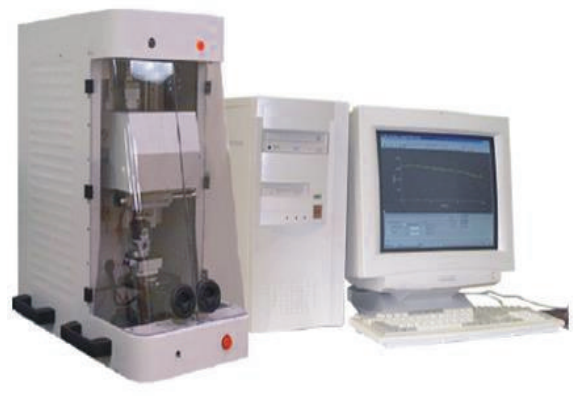

(a)

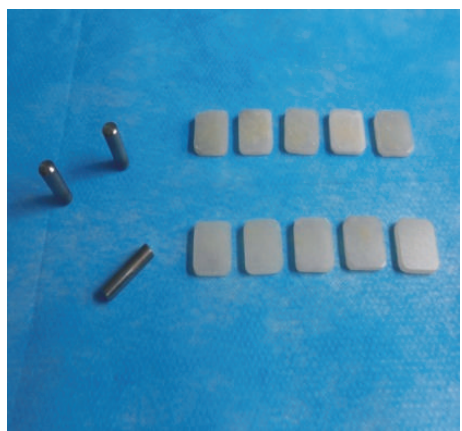

(b)

FIGURE 1: Equipment for the tribology experiment between simulated femoral stem and bone cement: (a) UMT-III universal multifunction tester; (b) titanium alloy and bone cement samples for tests.

region and then generate wear debris, among which $80 \%$ are less than $100 \mathrm{~nm}$. These debris are the key ones that induce the growth of fibrous tissue [25-28].

Though clinical reports and instigations revealed the bioreaction, which means reconstruction of femur, of the destruction of human bone caused by wear debris, few researches interpreted the wear mechanism over the course of micromotion and studied the morphology and size of wear debris. This study, which aims to act as a supplement, provides further investigation of bioreaction of wear debris with proof.

\section{Materials and Methods}

2.1. Experiment Equipment and Materials. The experiment will be made on UMT-III microfriction and wear tester (as illustrated in Figure 1(a), UMT-III, Centre for Tribology Inc., Campbell, CA, USA) produced by USA Center Company. Medical titanium alloy Ti6Al4V pins are adopted with a diameter of $4 \mathrm{~mm}$ and a height of $10 \mathrm{~mm}$, which were manufactured to simulate the femoral stem; the average roughness arranges from $0.03 \sim 0.06 \mu \mathrm{m}$ [17]. Bone cement is made into rectangle blocks of $12 \mathrm{~mm}$ long, $8 \mathrm{~mm}$ wide, and $4 \mathrm{~mm}$ high in model making process (as illustrated in Figure 1(b), Synthetic Material Research Institute, Tianjin, China), and the surface roughness is $0.3 \mu \mathrm{m}$. Mechanical property and compositions of the tested materials are as follows in Tables 1, 2, and 3 $[29,30]$.

2.2. Tribological Experiment. Orthogonal fretting wear test of twenty-four samples on titanium alloy and bone cement interface is conducted under different loads and amplitudes. Flat-flat contact model wear test is made in the following conditions (as illustrated in Figure 2), $25^{\circ} \mathrm{C}$ indoor temperature, 55\% 60\% humidity, dry friction, and $25 \%$ calf serum lubricants (Sijiqing Biological Engineering Materials Co. Ltd., Hangzhou, China) in nylon mould: $D$ (displacement) $= \pm 30$, \pm 40 and $\pm 50 \mu \mathrm{m} ; F_{n}$ (contact normal loads) $=20 \mathrm{~N}, 40 \mathrm{~N}$, $60 \mathrm{~N}$, and $80 \mathrm{~N}$; the corresponding pressure is $2.75 \mathrm{MPa}$, 3.89 $\mathrm{MPa}, 4.72 \mathrm{MPa}$, and $5.45 \mathrm{MPa}[16,17,19]$, respectively. According to the ISO5833 standard, Zhang and Ge found the maximum compression strength of bone cement researched

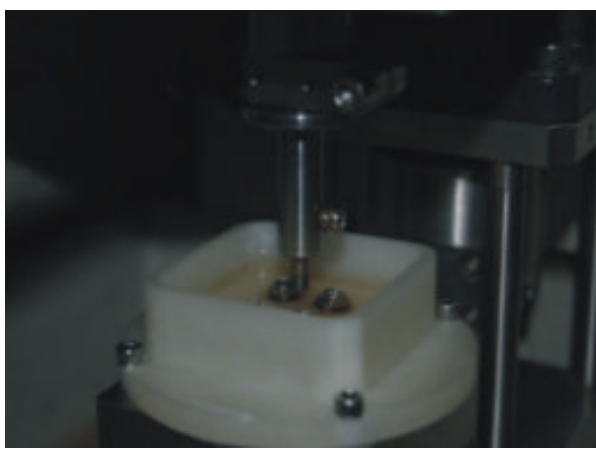

FIGURE 2: Reciprocating fretting friction test.

96.26 MPa [31]. Compared with the maximum contact pressure $64.9 \mathrm{MPa}$ in the study conducted by Zhang et al., this contact pressure could be accepted for the fretting wear test [17]. This was calculated on the basis of the following equations for the contact pressure of cylindrical pads on a plane specimen configuration, according to the Hertz theory [14]. The contact pressure was comparable to the normal contact stress at the stem-bone cement interface, which would be dominant following debonding of the femoral stem from the cement mantle $[6,19]$ :

$$
\begin{aligned}
P_{0} & =\sqrt{\frac{P E^{*}}{\pi R}}, \\
\frac{1}{E^{*}} & =\left(\frac{1-v_{1}^{2}}{E_{1}}+\frac{1-v_{2}^{2}}{E_{2}}\right) .
\end{aligned}
$$

In order to accelerate the test of the gait cycle frequency of $1 \mathrm{~Hz}$, fretting frequency $f=3 \mathrm{~Hz}$ and the cycle period of $5 \times 10^{4}$ times were selected. This frequency was chosen to accelerate the wear simulation but not to affect the results much [23].

A total of forty-eight samples were divided into two groups to conduct two tests, and each one contains 24 orthogonal tests. Before each test, the specimens including the metallic pin and the bone cement disk were cleaned in an ultrasonic bath using acetone and deionized water for $15 \mathrm{~min}$ 


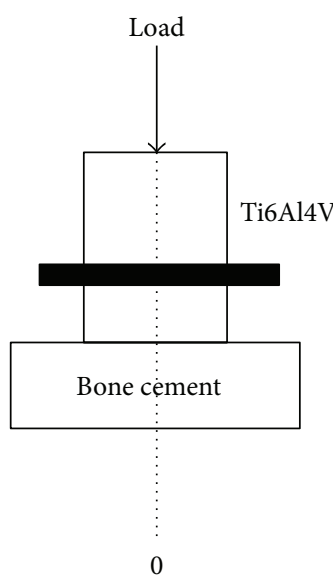

(a)

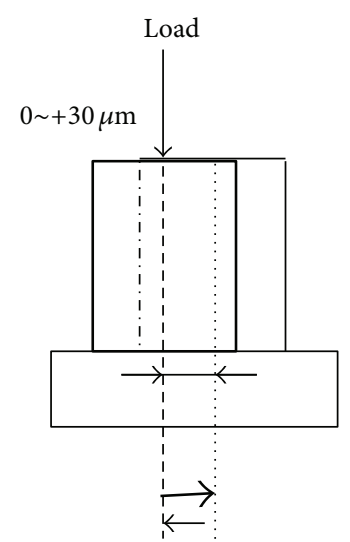

Friction force

(b)

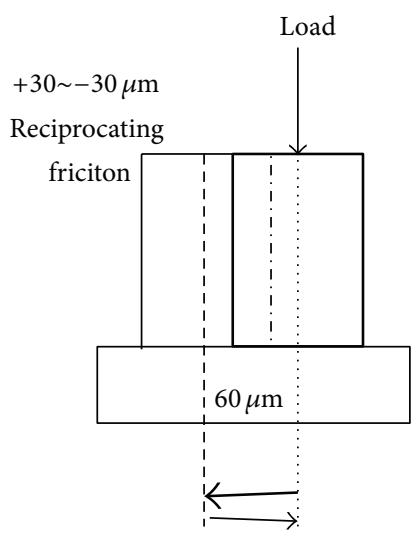

Friction force decrease

(c)

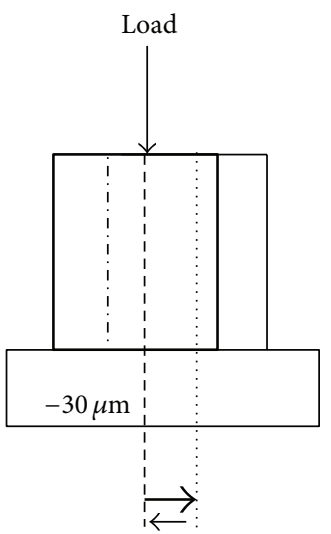

Friction force

(d)

Figure 3: Titanium alloy and bone cement interface fretting wear operation illustration: (a) under the load of $20 \mathrm{~N}, 40 \mathrm{~N}, 60 \mathrm{~N}$, and $100 \mathrm{~N}$, respectively, Ti6Al4V and bone cement interface contact; (b) fretting starting amplitude; (c) $60 \mu \mathrm{m}$ move back; (d) to lateral $30 \mu \mathrm{m}$, namely, move back to the original location, forming a wear cycle period.

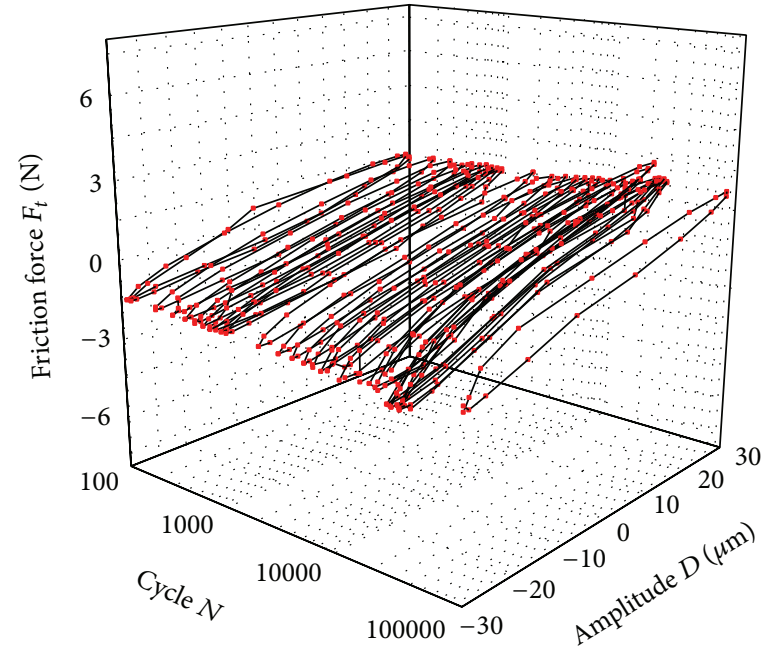

(a) $F_{n}=20 \mathrm{~N} \& D= \pm 30 \mu \mathrm{m}$ (dry friction)

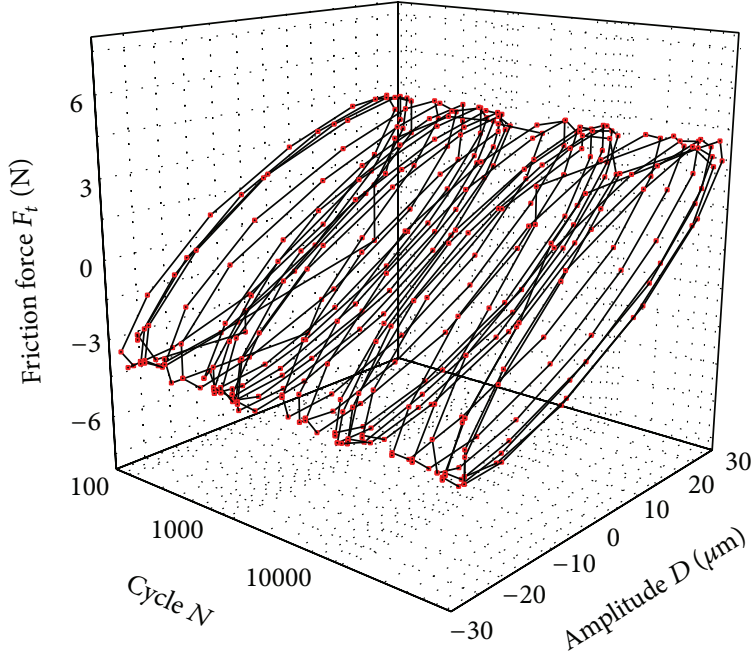

(c) $F_{n}=20 \mathrm{~N} \& D= \pm 30 \mu \mathrm{m}$ (in calf serum medium)

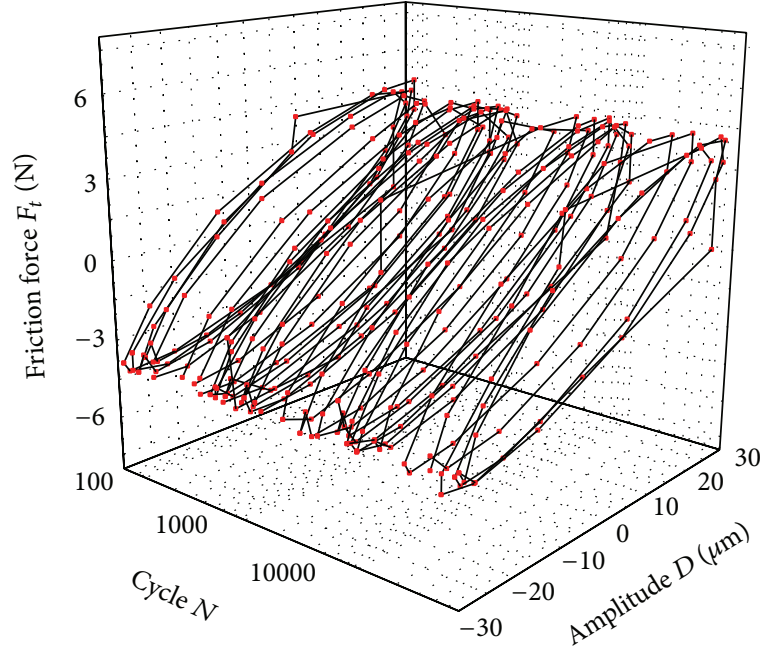

(b) $F_{n}=60 \mathrm{~N} \& D= \pm 30 \mu \mathrm{m}$ (dry friction)

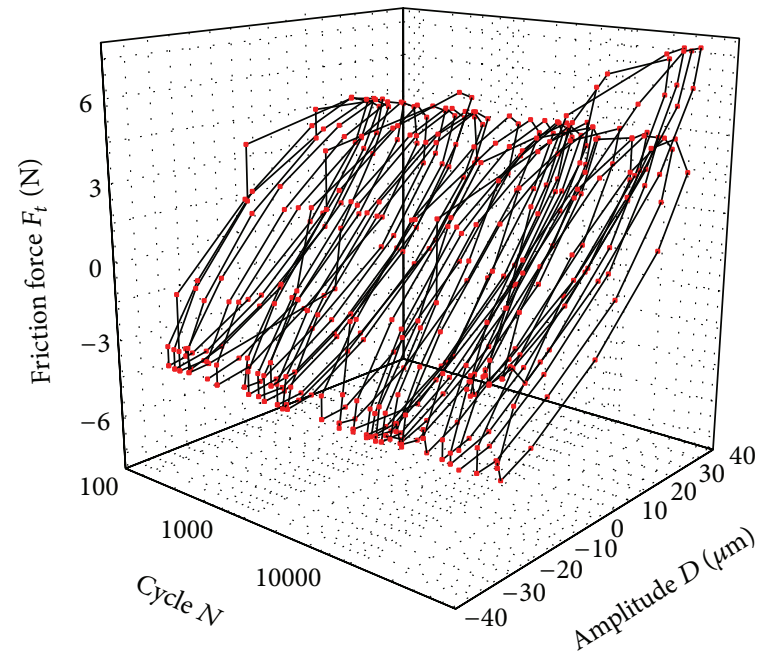

(d) $F_{n}=60 \mathrm{~N} \& D= \pm 30 \mu \mathrm{m}$ (in calf serum medium)

FIGURE 4: $F_{t}-D-N$ 3D curves of fretting wear of titanium alloy and bone cement in different medium and under different loads. 
TABLE 1: Mechanical property of the tested materials.

\begin{tabular}{lccccc}
\hline $\begin{array}{l}\text { Mechanical } \\
\text { properties }\end{array}$ & $\begin{array}{c}\text { Yong's modulus } E \\
(\mathrm{GPa})\end{array}$ & Poisson's ratio & $\begin{array}{c}\text { Yield stress } \\
(\mathrm{MPa})\end{array}$ & $\begin{array}{c}\text { Ultimate tesnile } \\
\text { strength }(\mathrm{MPa})\end{array}$ & $\begin{array}{c}\text { Hardness } \\
(\mathrm{Hv})\end{array}$ \\
\hline Ti6Al4V & 110 & 0.3 & 830 & 902 & 331 \\
PMMA & 2.5 & 0.39 & 65 & 75 & 21 \\
\hline
\end{tabular}
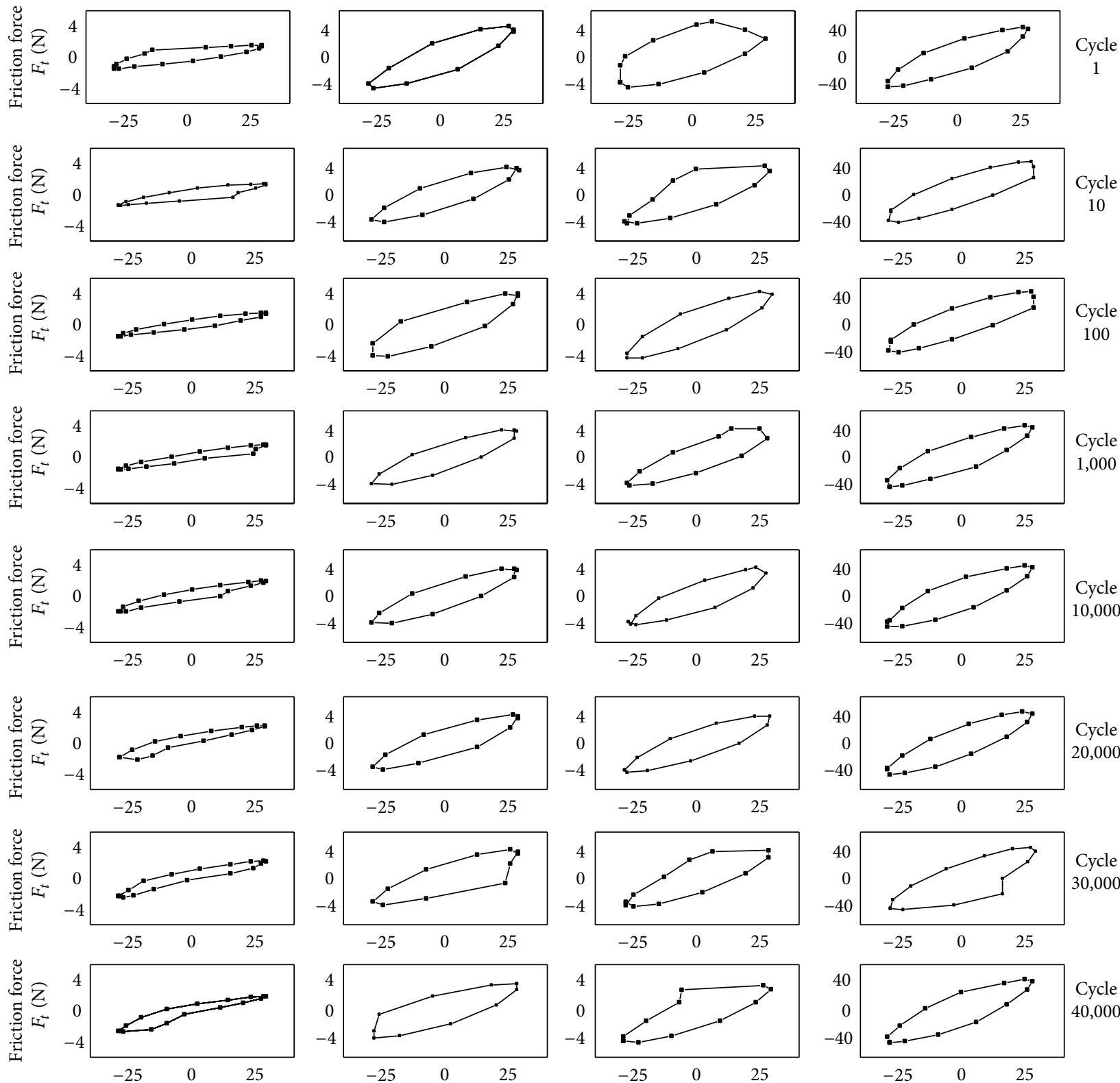

Cycle
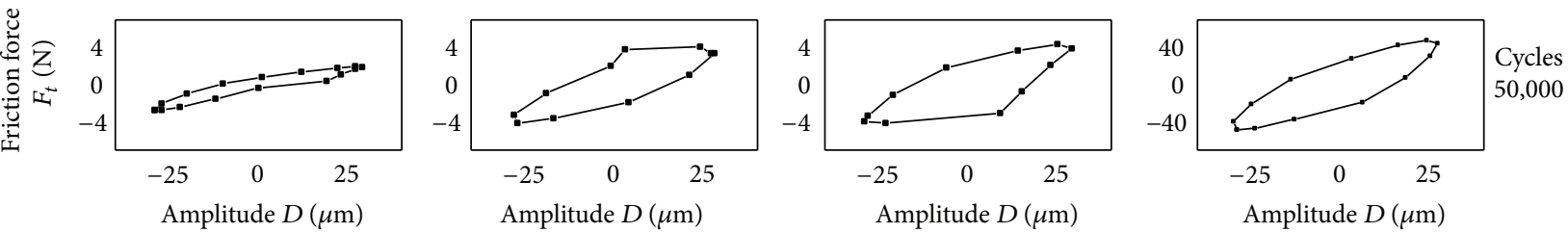

$\rightarrow 20 \mathrm{~N}$

$\rightarrow 40 \mathrm{~N}$

$-60 \mathrm{~N}$

$\rightarrow-80 \mathrm{~N}$

Figure 5: $F_{t}-D$ hysteresis loops $( \pm 30 \mu \mathrm{m})$ of titanium alloy and bone cement under different loads in dry test. 


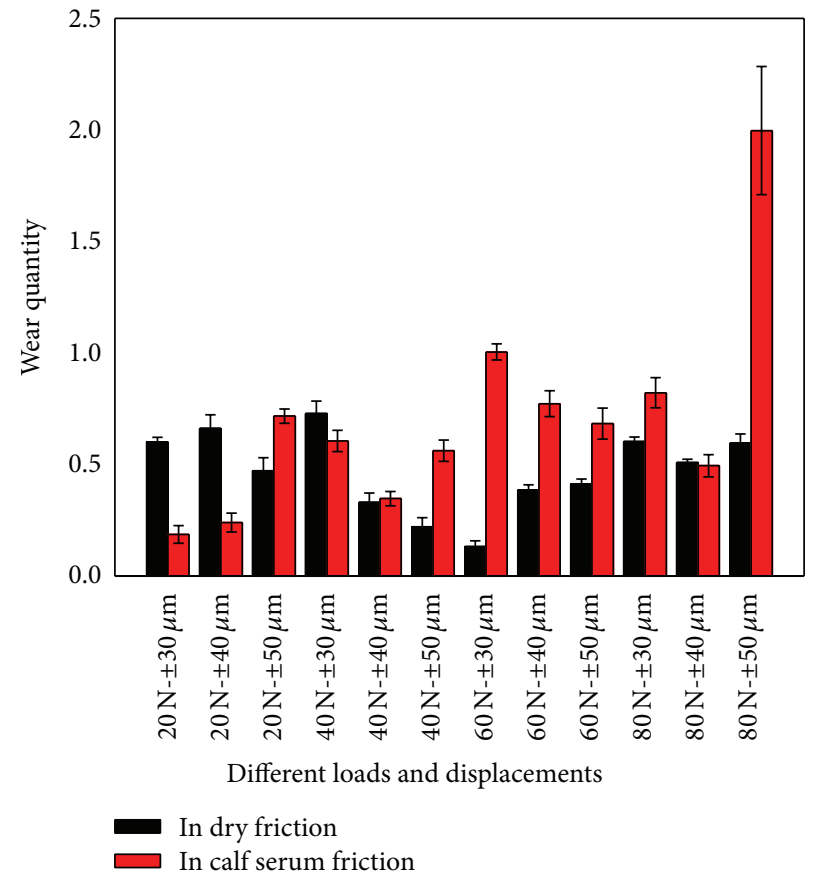

FIGURE 6: Bone cement sample fretting wear quantity.

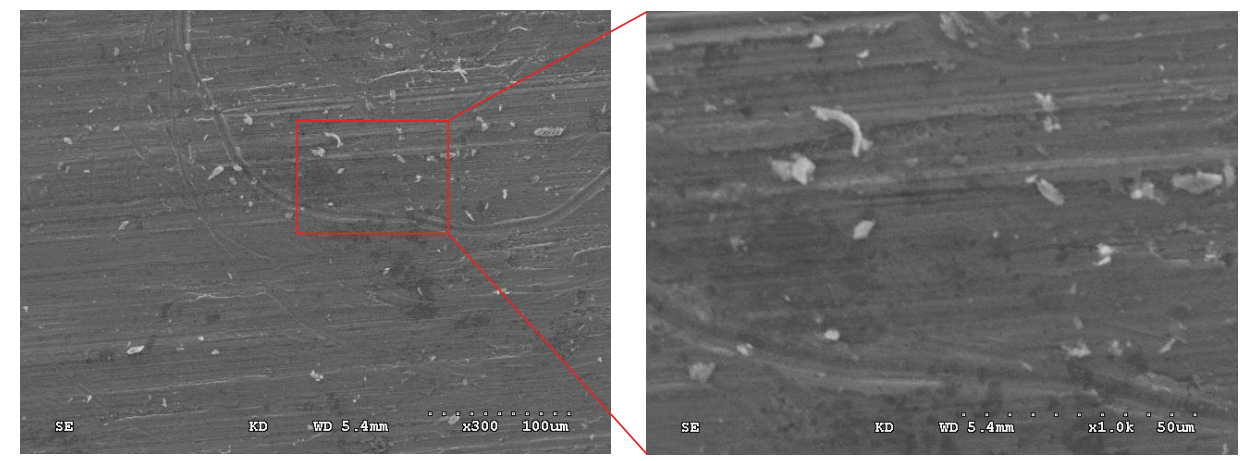

FIGURE 7: SEM graph of bone cement wear debris group.

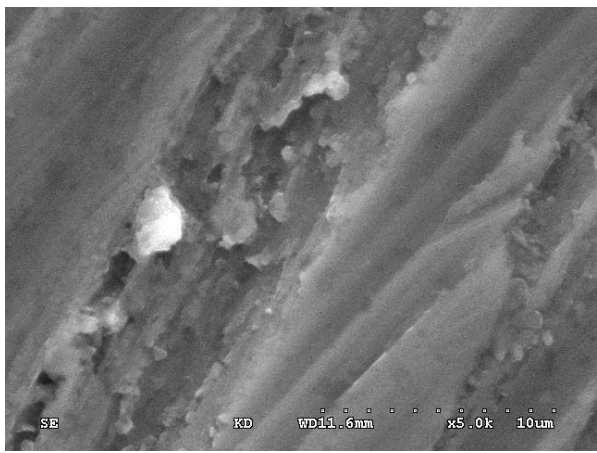

(a)

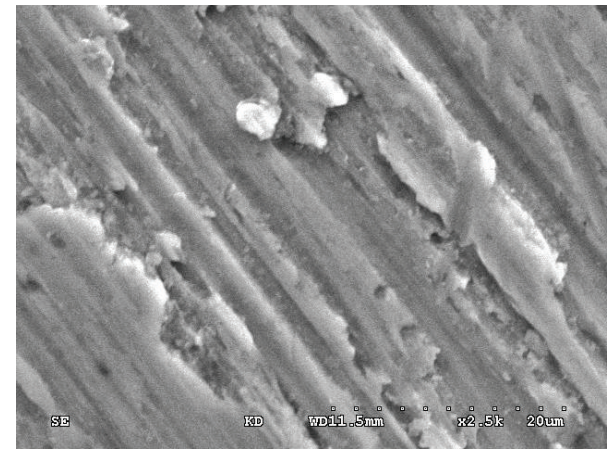

(b)

Figure 8: Morphology figure of bone cement spheral wear debris. 


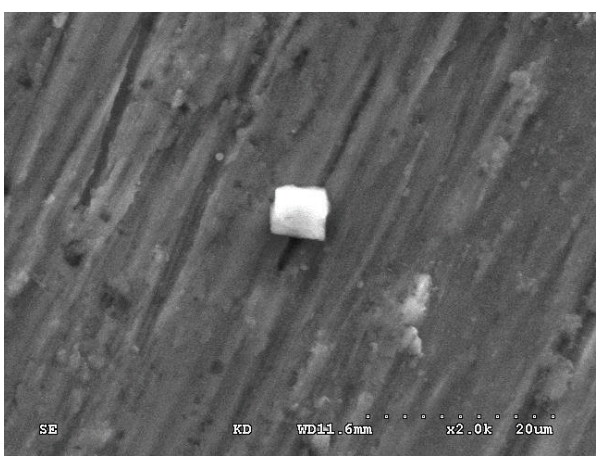

(a)

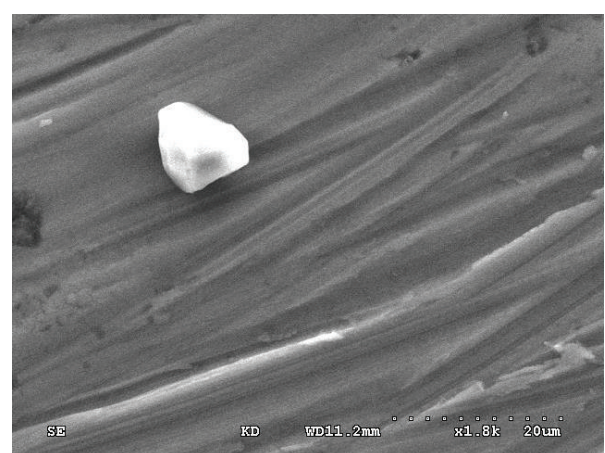

(b)

FiguRE 9: Tuberous wear debris of bone cement.

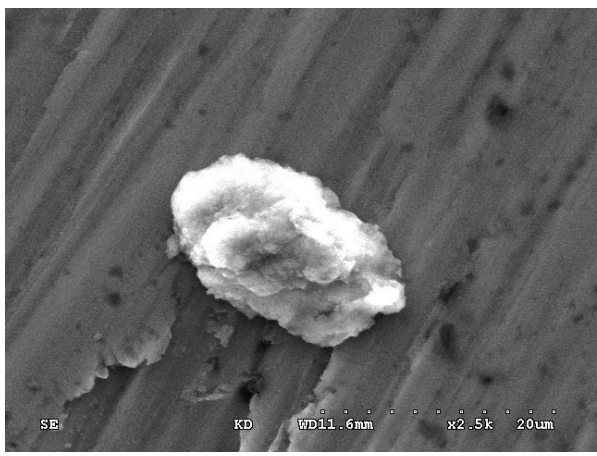

(a)

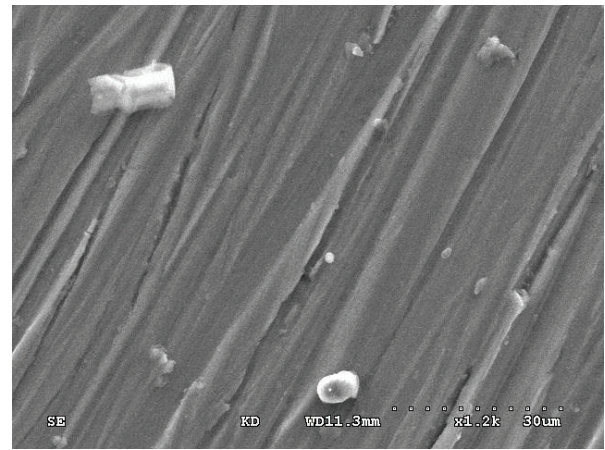

(b)

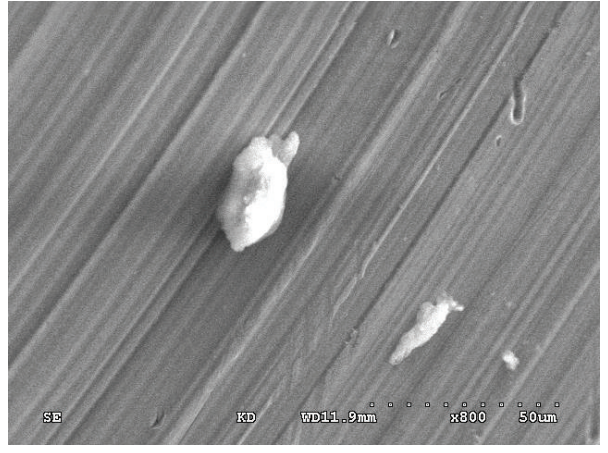

(c)

FIgURE 10: Morphology figure of bone cement mussy ellipse wear debris.

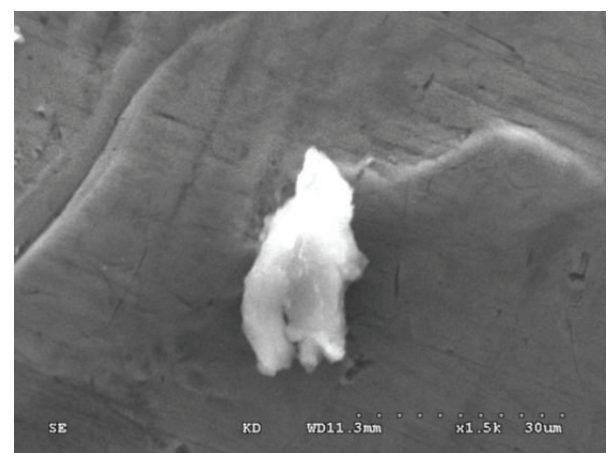

FIGURE 11: Lacerated wear debris of bone cement.
TABle 2: Chemical composition of Ti6Al4V (\%).

\begin{tabular}{cccccccc}
\hline $\mathrm{Al}$ & $\mathrm{V}$ & $\mathrm{Fe}$ & $\mathrm{O}$ & $\mathrm{C}$ & $\mathrm{N}$ & $\mathrm{H}$ & $\mathrm{Ti}$ \\
\hline 6.02 & 4.1 & 0.168 & 0.043 & 0.16 & 0.02 & 0.001 & 89,488
\end{tabular}

each followed by drying with an $\mathrm{N}_{2}$ gas jet. After each test, the metallic pin and the bone cement disk were removed from the testing apparatus, dried with the $\mathrm{N}_{2}$ gas jet [17].

2.3. Evaluation of the Experiment. Draw fretting movement figure $\left(F_{t}-D-N\right)$ on the basis of experiment data $\left(F_{t}\right.$ stands for Friction stress and $N$ stands for cycles), analyze the 


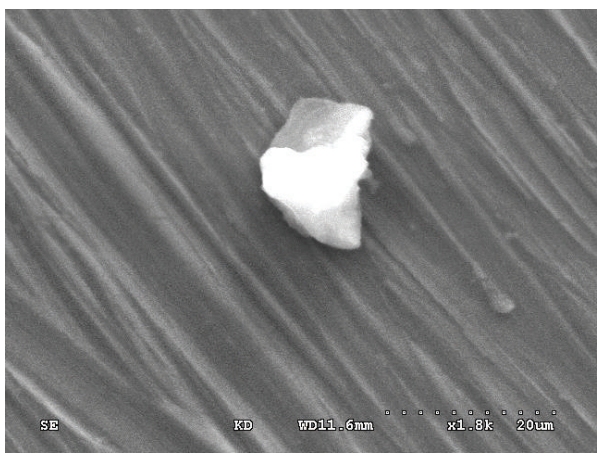

(a)

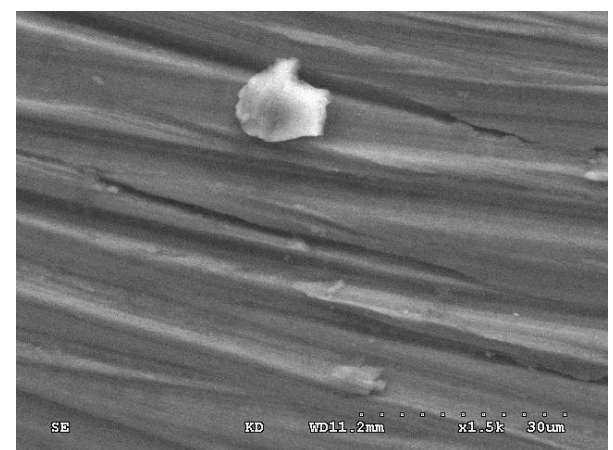

(b)

FIGURE 12: Sheet wear debris of bone cement.

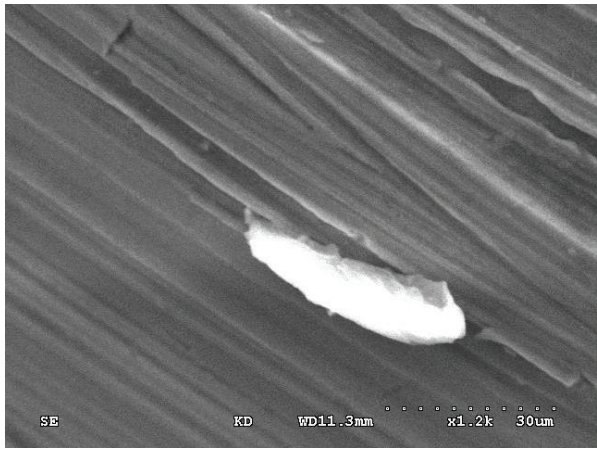

(a)

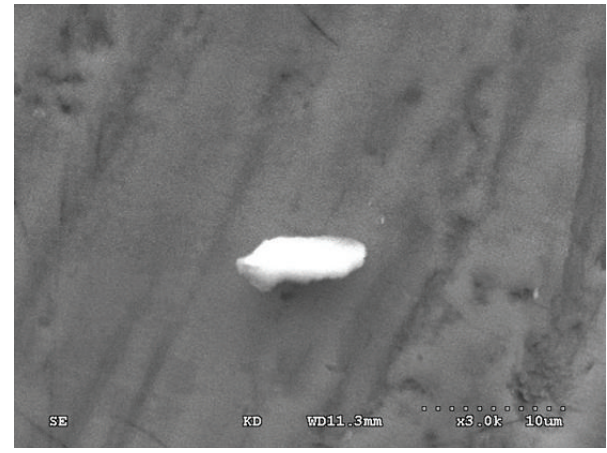

(b)

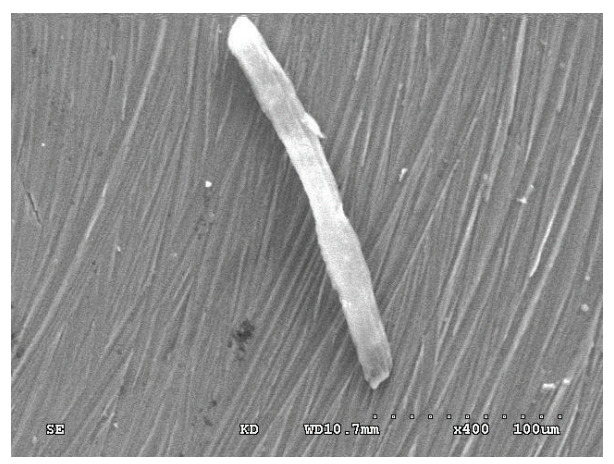

(c)

FIGURE 13: Morphology figure of bone cement strip wear debris.

TABLE 3: Composition of CEMEXXL bone cement.

\begin{tabular}{lc}
\hline Liquid ingredients & $18.33 \mathrm{~g}$ \\
\hline Methyl methacrylate & $98.20 \%$ \\
Dimethyl acetal toluic acid & $1.80 \%$ \\
Hydroquinone & $7.5 \times 10^{-5} \%$ \\
\hline Powder ingredients & $50 \mathrm{~g}$ \\
\hline $\mathrm{BaSO}_{4}$ & $85.00 \%$ \\
Polymethyl methacrylate & $12.00 \%$ \\
Benzoyl peroxide & $3.00 \%$ \\
\hline
\end{tabular}

movement characteristics of fretting wear region on friction interface, make statistics on bone cement matrix's wear extent, and draw wear microgram further. Quanta 200 ESEM FEG scanning electron microscope (SEM, FEI, Eindhoven, Netherlands) is applied separately in collecting wear scar feature on the stem-bone cement interface, and analysis is made on the debris shape and its generating mechanism.

Titanium alloy and bone cement interface fretting is a reciprocating process (Figure 3(a)). Take $30 \mu \mathrm{m}$ starting fretting amplitude for instance, move $30 \mu \mathrm{m}$ aside and the friction force occurs, the rear end of Ti6Al4V metal material wears with bone cement, which makes an edge wear of $30 \mu \mathrm{m}$ approximately and the wear scrap accumulation (Figure 3(b)). Shift back $60 \mu \mathrm{m}$ in unloading; the titanium 


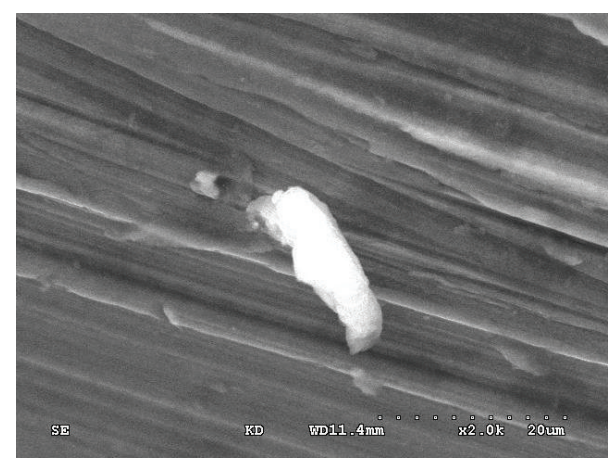

FIGURE 14: Morphology figure of bone cement pole-shaped wear debris.

alloy has tip shift back and wear at $\pm 30 \mu \mathrm{m}$ place and makes $30 \mu \mathrm{m}$ wear (Figure 3(c)). Shift the detector aside $30 \mu \mathrm{m}$ to its original place, and forms a wear cycle motion (Figure 3(d)).

\section{Results}

3.1. Mechanism of Fretting Operation. In purpose of analyzing the process of fretting movement, $F_{t}-D-N$ curves are being analyzed when $F_{n}=20 \mathrm{~N}$ and $D= \pm 30 \mu \mathrm{m}$ and $F_{n}=$ $60 \mathrm{~N}$ and $D= \pm 30 \mu \mathrm{m}$, respectively. Figure 4 shows the fretting operation of titanium alloy surface and bone cement matrix under the circumstances of dry friction and calf serum lubricants. In dry friction, when $F_{n}=20 \mathrm{~N}$ and $D= \pm 30 \mu \mathrm{m}$, $F_{t}-D$ curve is in shape of parallelogram at early stage, while with the increase of fretting cycle, when $N \approx 2000, F_{t}$ $D$ curve transforms into straight line gradually (Figure 4). When $F_{n}=60 \mathrm{~N}$ and $D= \pm 30 \mu \mathrm{m}$ (in Figure 4(b)), the distance between loading upper curve and unloading lower curve increases, which illustrates the energy consumption at early stage is slightly higher; meanwhile, when $N \approx 1000$, $F_{t}-D$ curve transforms into ellipse. When $N=5000$, the distance between loading upper curve and unloading lower curve decreases, which illustrates the energy consumption drop, whereas in calf serum lubricants, when $F_{n}=20 \mathrm{~N}$ and $D= \pm 30 \mu \mathrm{m}$, the $F_{t}-D$ curve transforms from parallelogram into ellipse $(0 \leq N \leq 1000)$, and when $N \approx 5000$, the curve transforms into flat ellipse (Figure $4(\mathrm{~d})$ ).

The $F_{t}-D$ curve transforming into parallelogram at early stage indicates that the contact area is completely in slippage and wear region, and because elasticity and plasticity transformations of different materials occur in contacting and cooperating process, three-matrix abrasion has not formed in friction surface; therefore, the energy consumption of microamplitude is slightly higher. When the load and cycle increase to a certain extent, the $F_{t}-D$ curve turns into ellipse gradually, which indicates that the tangential fretting operates in mixed region (the medium transition phase between the overall slippage and partial slippage of the interface). With the cycle increase, $F_{t}-D$ curve will close and transforms into flat ellipse, which indicates that the interface is in balance between elasticity and plasticity transformation and contact stiffness, partial slippage region, and adhesion region come into being on wear interface.
The size of fretting contact area, stress distribution, wear depth, and wear quantity are all determined by loads; $F_{t}-D$ curve in the same cycle changes with the increase of contact loads. As illustrated in Figure 5, when $N=1$ (1 cycle), $F_{t}-D$ curve $( \pm 30 \mu \mathrm{m})$ is basically parallelogram at the early stage, except that under $80 \mathrm{~N}$ load is ellipse at the early stage. There is no change when cycle period reaches $N=10$ (Figure 5) and under $20 \mathrm{~N}$ load, which indicates that the surface is still in the elastic area, whereas, when under the loads of $40 \mathrm{~N}$ and $60 \mathrm{~N}$, the $F_{t}-D$ curve transforms from parallelogram into ellipse gradually; for it is just the early stage of wear period, there is no obvious change in fretting diagram. When the load reaches $80 \mathrm{~N}$, obvious elasticity and plasticity transformations occur on the bone cement surface; yet $F_{t}-D$ curve remains unchanged. When the cycle period reaches $N=100 \sim$ 1000 (Figure 5), $F_{t}-D$ curves under different loads change gradually. When under $20 \mathrm{~N}$ load, the $F_{t}-D$ curve seems like parallelogram, while under $40 \mathrm{~N}$ and $60 \mathrm{~N}$ loads, the curves will change alternately between parallelogram and ellipse, which indicates that the wear interface begins to transit from slippage to partial slippage. Analyzing from Figure 4, we can find out from the fretting figure in hysteresis loops of $N=$ $20,000 \sim 40,000$ and under $20 \mathrm{~N}$ load that the original ellipse turns into lines gradually with the influence of cycles, which illustrates that the straight line slopes in the loading and unloading process are the same and the wear quantity remains stable. When under $40 \mathrm{~N}, 60 \mathrm{~N}$, and $80 \mathrm{~N}$, the $F_{t}-D$ curve has transformed into stable ellipse. When the cycle period reaches 5,000 cycles, $F_{t}-D$ curve remains stable; the fretting diagram under $20 \mathrm{~N}$ loads is linear while that under $40 \mathrm{~N}, 60 \mathrm{~N}$, and $80 \mathrm{~N}$ turns into stable ellipse.

3.2. Fretting Wear Quantity Analysis of Bone Cement Matrix. As illustrated in Figure 6, the wear quantity of bone cement sample increases with adding contact loads in different wear conditions, amplitudes, and loads. Some researches demonstrated that the proteins in fretting tribological behavior play a passive role in protecting the wear region [20-28]. Under the same contact load, the wear quantity of bone cement in the calf serum is greater than that in the air.

\subsection{Morphology Study on Wear Debris}

3.3.1. Morphology Study on Bone Cement Wear Debris. After transplanting the artificial stem into human's body, for the extremely rigid biological friction and wear environment on titanium alloy and bone cement interface, friction interrelated biomechanical changes are unpredictable and the wear period is relatively long; therefore wear types can be found out through the study on the interrelated wear debris appearance produced in friction. As shown in Figure 7, the bone cement wear debris are in various shapes, including the wear debris in strip, block, sheet, and ball shape and the different particle sizes. Some basic rules can be found out that the larger the size of the wear debris is, the more complicated the surface becomes, and the appearance of wear debris with smaller particle size transforms gradually into spherality or near spherality. After studying and observing the wear debris for 
several times, we find that it is a common and universal rule. The matrix of wear debris in SEM picture is titanium alloy, because the wear debris are so small that they could not be deprived from the friction contact surface.

(I) Spheral Wear Debris. The maximum and minimum debris sizes of spheral wear debris are basically $10 \mu \mathrm{m}$ and $1 \mu \mathrm{m}$ approximately, which distributes widely and is one kind of wear debris that exist in greatest amount. It can be found in Figure 8 that the surface texture of the spheral wear debris is quite smooth. It is inspected that wear debris with large particle sizes usually exist in shapes of block, sheet, or strip, whereas those with small particle sizes tend to be in spheral or near spheral shapes, which results from the cooperation of repeated rubbing in the reciprocating fretting wear and the debris wear, which is formed in the late period of wear debris abrasion. When the wear debris accumulate to a certain degree, they will be attached to bone bed and induce osteoclast activating factor to make broken bone physiological response under the joint capsule press and they are the main wear debris that induce hip aseptic joint replacement loosening.

(II) Tuberous Wear Debris. The length and width ratio of tuberous wear debris (Figure 9) is nearly $2 \mu \mathrm{m}$ with the spindle-shaped or flat tuberous appearance, and obvious lines rise and fall on its surface. Water prop shaped wear debris is mainly formed by adhesion wear and is always ripped or torn in the process, and its particle size is about $5 \mu \mathrm{m}$, while flat wear debris originate from the crack nuclear on friction surface caused by fatigue stress on the friction interrelated surface, which rips off at the weak bonding point of bone cement matrix under the friction interrelated adhesion, and its particle size is about $2 \sim 20 \mu \mathrm{m}$. The debris are formed at the interface debonding period, attached to the titanium alloy surface, and are the early product of fretting wear.

(III) Ellipse Wear Debris. The width and length ratio of ellipse wear debris is from 2 to 5 and the appearance takes the shape of ellipse (Figure 10). Obvious lines rise and fall on wear debris surface, which is mainly produced and developed from bone cement tuberous wear debris. Tuberous debris are polished into ellipsoid gradually under the reciprocating wear model and long term three-matrix abrasion, and the ellipsoid wear debris are the early forms of spheral wear debris with the particle size of 2 to $15 \mu \mathrm{m}$ approximately. This type of wear debris is formed under the repeated roller compacted damage of large bone cement tuberous wear debris ripped off.

(IV) Lacerated Wear Debris. Lacerated wear debris originates from the dropping of asperity slippage wear which makes cracks on matrix surfaces, for wear debris produces in the same direction with that of crack extension, the existing parts peel off from matrix under cutting and furrowing, together with fatigue wear, lacerated wear debris come into being. This type of debris has irregular and coarse edge line and the particle size is $5 \sim 35 \mu \mathrm{m}$ (Figure 11), which is formed at the fatigue wear stage.

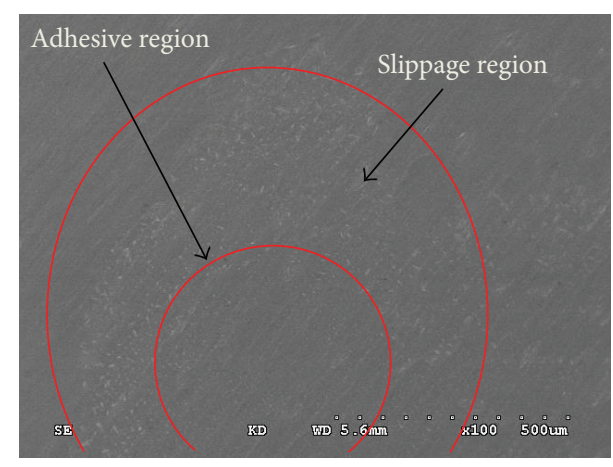

FIGURE 15: SEM Morphology graph of Ti6Al4V alloy wear debris group.

(V) Sheet Wear Debris. Sheet wear debris has relatively large area and small thickness and takes the shape of irregular polygon (Figure 12). It is mainly because the tiny materials peel off between surface and subsurface under fatigue effect and then, attached to material surface, sheet wear debris is formed after reciprocating press, and its particle size is 20 to $50 \mu \mathrm{m}$. This kind of wear debris is formed at the fatigue wear stage.

(VI) Strip Wear Debris. Pole-shaped wear debris has a diversified structure in appearance. There are mainly three formation reasons for strip wear debris; firstly, the matrix is ripped off the matrix in scraping action; secondly, wear debris are formed in the friction process; thirdly, sheet wear debris are rubbed into rope shaped wear debris in friction interrelated motion, which reflects the motion state of reciprocating fretting wear, and the length of wear debris is 15 to $110 \mu \mathrm{m}$ (Figure 13). It is the derived product of ellipsoid wear debris and it is formed at the middle and late stages.

(VII) Pole-Shaped Wear Debris. Pole-shaped wear debris has a diversified structure in appearance, curvy edge line, and stable surface lines, and its size is 5 to $30 \mu \mathrm{m}$. There are two main reasons for the formation of pole-shaped wear debris; firstly, debris are produced in thermoplastic transformation and microcutting. Pole-shaped wear debris are usually produced in breaking in period with the size of $10 \sim 50 \mu \mathrm{m}$. Secondly, it is formed because of the falling furrow edge drop in surface cutting, and its size is 10 to $80 \mu \mathrm{m}$ (Figure 14). Pole-shaped wear debris are generated at the same stage with strip wear debris and then suffer from abrasive wear.

3.3.2. Morphology Study on Titanium Alloy Wear Debris. It can be found in Figure 15 that titanium alloy wear debris are small in size and most of which take the irregular 


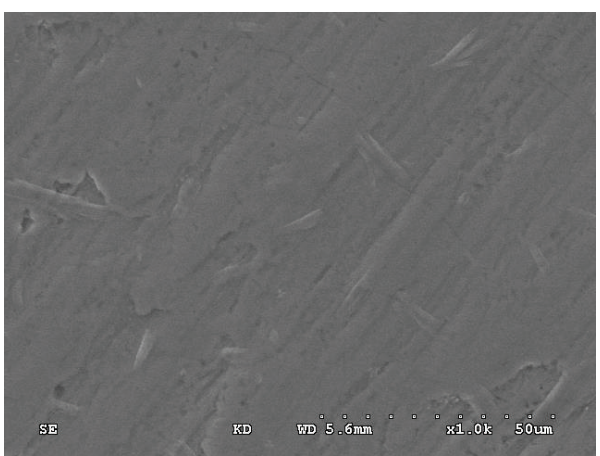

(a)

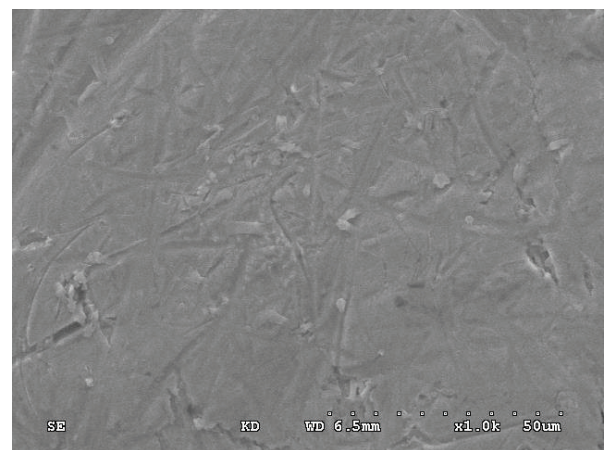

(b)

FIGURE 16: Morphology figure of titanium alloy strip wear debris: (a) debris in dry condition; (b) debris calf serum.

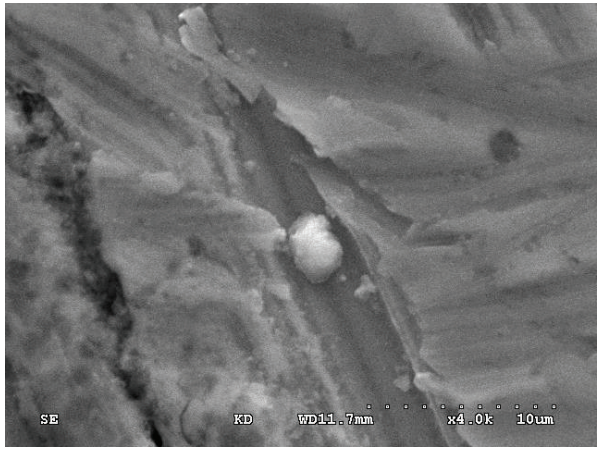

(a)

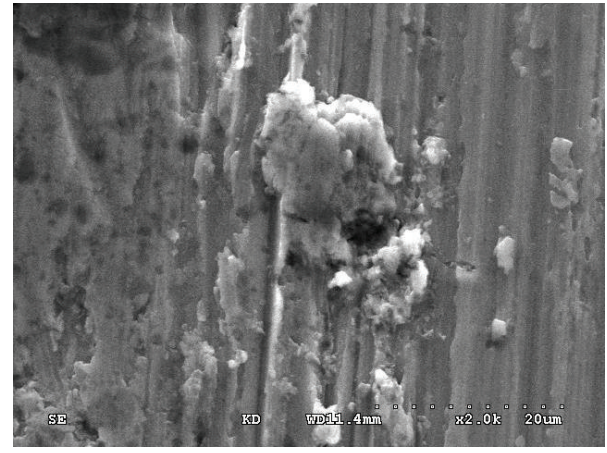

(b)

FIGURE 17: Morphology figure of titanium alloy spheral wear debris.

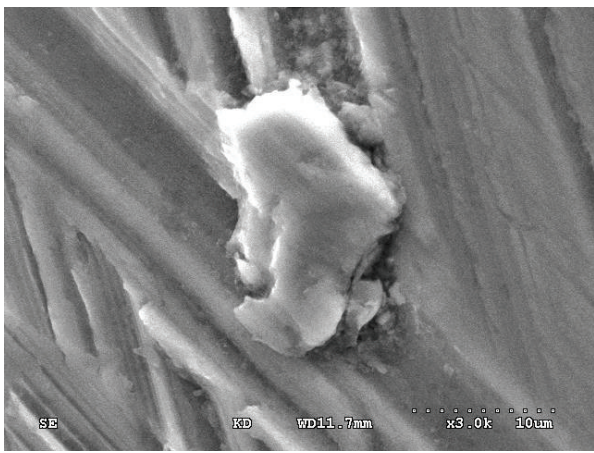

(a)

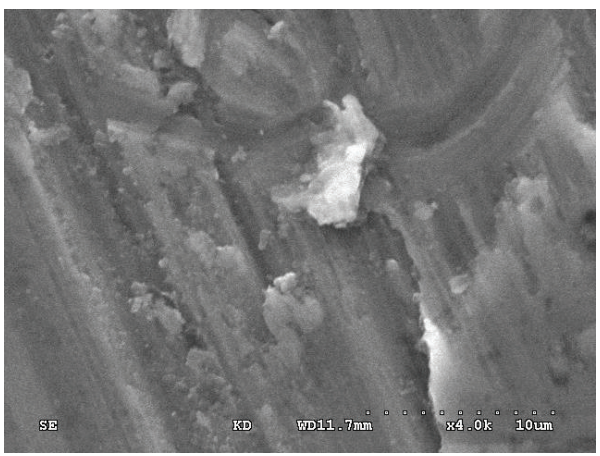

(c)

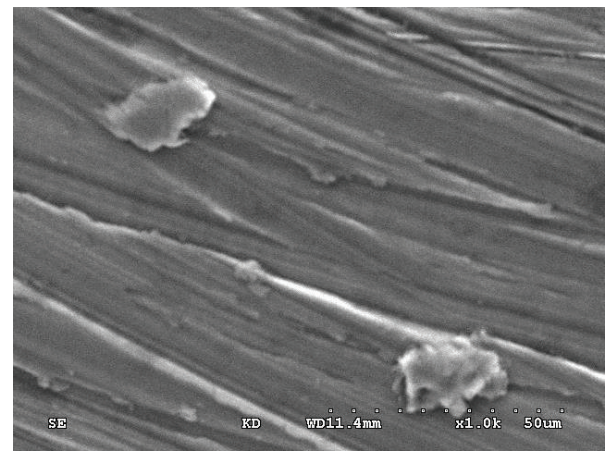

(b)

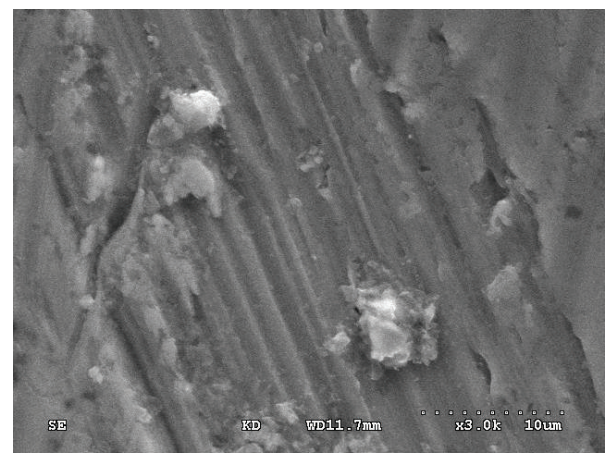

(d)

FIGURE 18: Morphology figure of titanium alloy tuberous wear debris. 


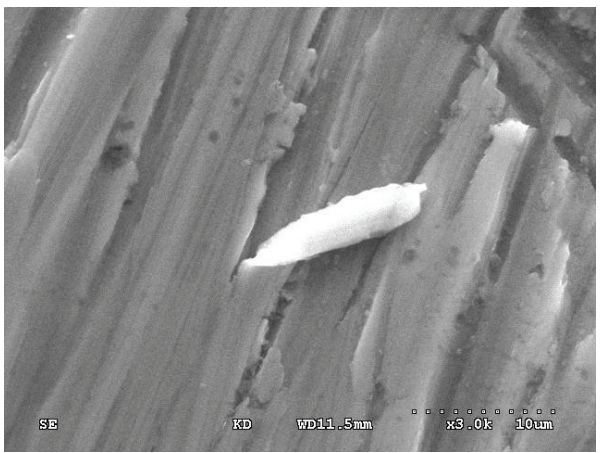

(a)

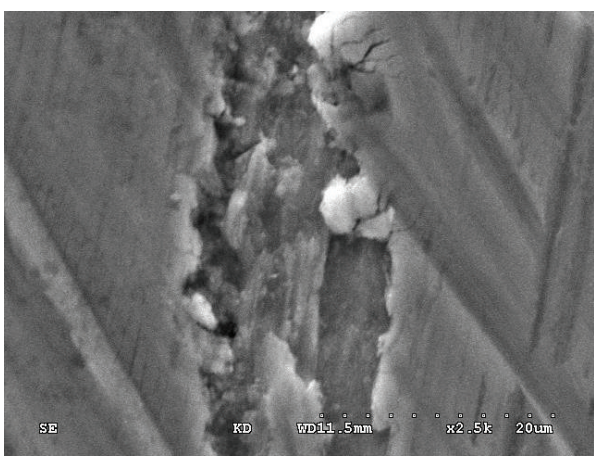

(c)

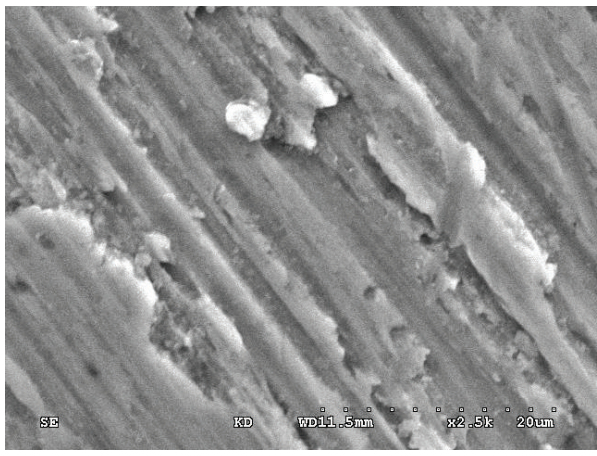

(e)

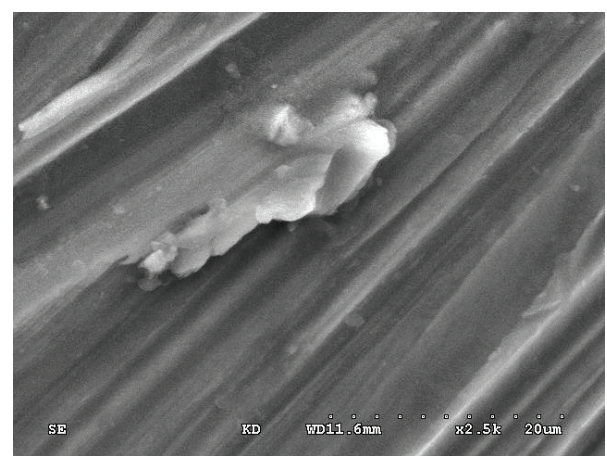

(b)

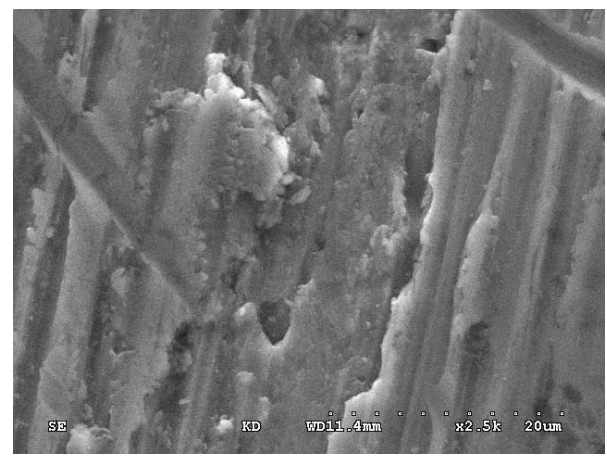

(d)

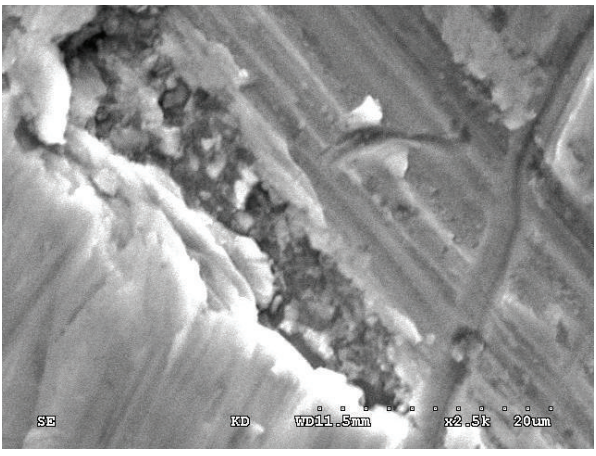

(f)

FIGURE 19: Morphology figure of titanium alloy lacerated wear debris.

shapes. Though its modulus of elasticity is higher than that of the bone cement, the inserted metals exist in long-term complicated fatigue damage conditions, which will accelerate the crack extension on wear surface and lead to the formation of wear debris at last and the generation of osteoclast factors. Therefore, study on titanium alloy wear debris' forms is quite significant.

(I) Strip Wear Debris. Strip wear debris is commonly seen in titanium alloy wear debris group with the size of 10 to $50 \mu \mathrm{m}$. It has rather smooth surfaces and there are various reasons for its formation. First of all, the previously ripped small titanium alloy wear debris transform gradually into abrasive wear form in fatigue wear process. On the other hand, the large sheet wear debris' edges are hardened and become thin and sharp which scrapes titanium alloy matrix in friction process. Such kind of wear debris has rather sharp wings; the existing wear debris on friction surface generated in fretting wear process come into being (Figure 16) at the late stage.

(II) Spheral Wear Debris. Spheral wear debris of titanium alloy in spheral shape are shown in Figure 17(a) which are small in size and whose distribution scopes are usually smaller than $15 \mu \mathrm{m}$. There are uneven lines on the surface and many debris gather around. (Figure 17(b)). They are mainly the products of fatigue wear and adhesion wear caused by the broken large wear debris which come into being in titanium alloy fretting wear. In addition, the falling debris cannot escape from wear region easily and finally the spheral wear debris comes into being with the size of 1 to $30 \mu \mathrm{m}$ approximately. This type of wear debris is formed in the late period of fatigue wear. 


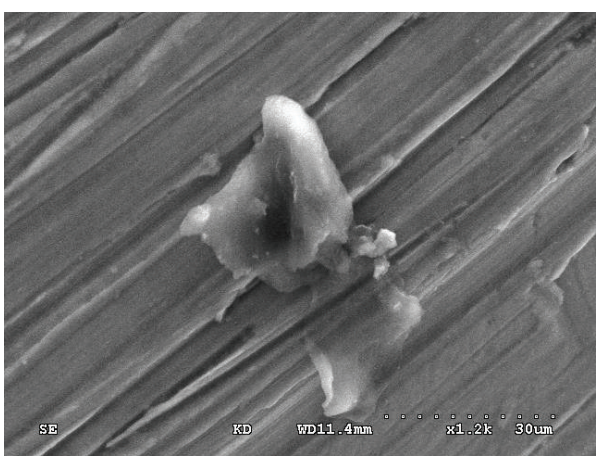

(a)

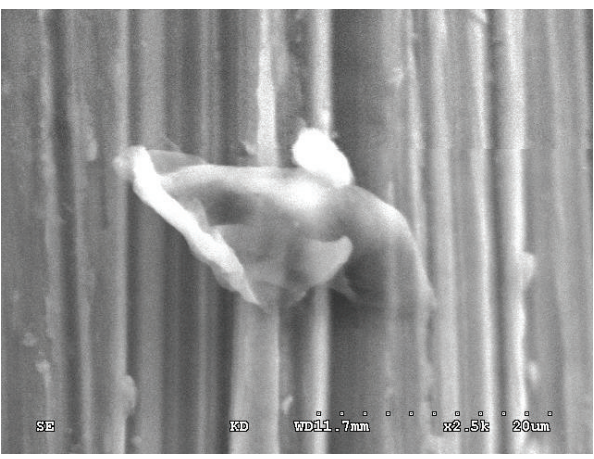

(c)

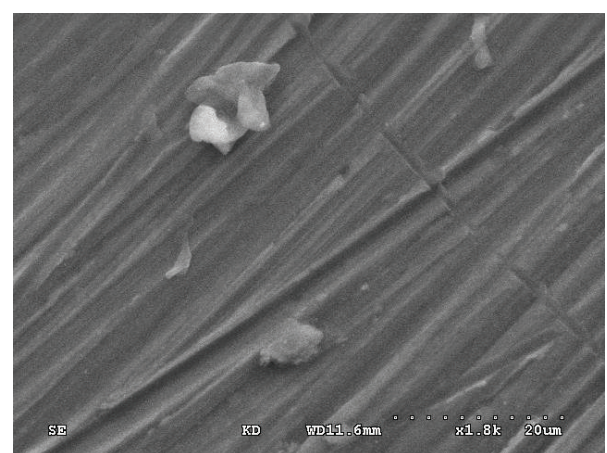

(b)

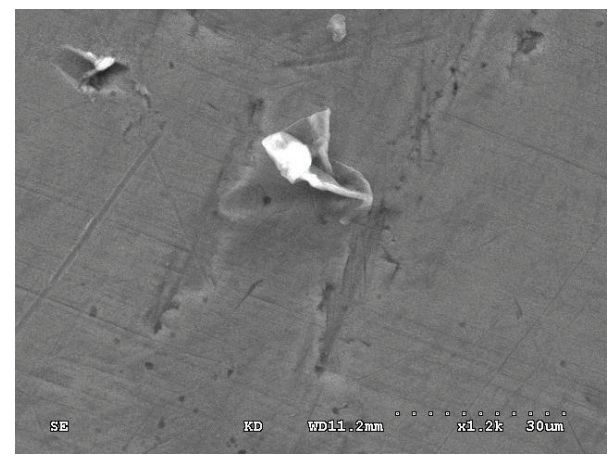

(d)

FIGURE 20: Morphology figure of titanium alloy sheet wear debris.

(III) Tuberous Wear Debris. Wear debris of this type are spindle-shaped (Figures $18(\mathrm{a})$ and $18(\mathrm{~b})$ ) or in flat shape (Figures 18(c) and 18(d)) with a small width and length ratio and complicated edge outlines, and there are uneven lines even obvious scars. Spindle-shaped wear debris come mainly from adhesion wear with a size of 5 to $100 \mu \mathrm{m}$, while the flat wear debris are formed because the crack nuclei formed on friction surface under the fatigue stress on the friction interrelated surface peel off and tear away from matrix at the weak bonding point of matrix materials under the effect of interface adhesion, and their distribution scopes are 5 to $50 \mu \mathrm{m}$. They originate from lacerated wear formation and come into being at the mid-term stage of fatigue wear.

(IV) Lacerated Wear Debris. Lacerated wear debris are the products of friction interrelated reciprocating motion with irregular and coarse surface and uneven lines on the surface which give people the sense of hierarchy and mainly from the falling debris from titanium alloy matrix under the fretting fatigue effect (Figures 19(a) and 19(b)). With the cycle load, cracks on fatigue wear edges extend in vertical direction with wear direction (Figures 19(c) and 19(d)). The successive wear accelerates the ripping of titanium alloy surface and then the wear debris come into being. The common size distribution scope is 5 to $50 \mu \mathrm{m}$ and titanium alloy extends in different sizes from partial peeling to complete peeling which makes the wide distribution of wear particle size (Figures 19(e) and 19(f)). This kind of wear debris is formed at the early stage of fatigue wear.

(V) Sheet Wear Debris. The titanium alloy sheet wear debris have relatively wide size distribution ranging within the scope between 5 and $60 \mu \mathrm{m}$ and smooth surface. There are two reasons for the formation. On the one hand, the early stripping tuberous debris of titanium alloy transform and harden in fretting wear process, and for the hardness and tension are higher than those of the matrix, therefore this type of wear debris comes into being. On the other hand, the fatigue peeling occurs on the wear surface of large titanium alloy under the effect of fretting wear which is broken into wear debris in smaller sizes in the reciprocating wear motion (Figure 20). This type of wear debris originates from tuberous wear debris and forms at the late stage of fatigue wear.

These results, which were consistent with other clinical results in other literature, proved that the particles shaped like spherical, sheet, and so forth were the main reason why a series of bioresponses like the increase of osteoclast were induced [32, 33]. Also, through the analysis of the morphology of wear debris, not only did this paper refine the research used to be analyzed just from the aspect of size in clinic but also it provided further analysis of the bioresponses induced by different morphology and size of the wear debris with evidence. 


\section{Conclusions}

In this study, the fretting wear mechanism and debris analysis at the stem-bone cement interface under fretting wear were investigated through a series of frictional tests. The following conclusions can be drawn from this work.

(1) Compared with hysteresis loops under different loads and displacements, the result shows that elasticity and plasticity performance of the frictional interface materials can be damaged by fretting fatigue. In addition, material energy dissipation will increase periodically.

(2) The wear quantity of the bone cement is mainly influenced by load and displacement. As load increases, the albumin passive film gradually fails to protect the wear interface. The maximum of the wear loss between stem and bone cement for displacement $100 \mu \mathrm{m}$ and load $80 \mathrm{~N}$ could reach $1.997 \mathrm{mg}$.

(3) Bone cement wear debris' size distribution is relatively widely spread from 1 to $110 \mu \mathrm{m}$. The bone cement wear debris in tuberous, tear, and sheet shapes are formed at the early interface ripping stage, while sheet and strip wear debris will be affected by fatigue wear and reciprocating acts, respectively. The spheral wear debris is the main wear debris. Titanium alloy wear debris's size ranges from 5 to $150 \mu \mathrm{m}$, and tuberous and sheet wear debris are formed at the early and middle stage. Tear-shaped wear debris are affected by fatigue wear while sphere and trip wear debris are formed at the late stage under the influence of wear acts. In this paper, fretting wear properties and morphology and the size distribution of the wear debris were detected in fretting wear test [32-39], which was consistent with the results of the size of wear debris in other literature. Moreover, different morphology of titanium alloy and bone cement debris was listed in this paper according to the classification of morphology, which served as a complement in this research.

\section{Conflict of Interests}

The authors declared that they have no conflict of interests regarding the publication of this work.

\section{Acknowledgments}

This work is supported and sponsored by Qing Lan Project and the Scientific Innovation Research of College Graduate in Jiangsu Province (no. KYLX_1376).

\section{References}

[1] W. H. Harris, "The problem is osteolysis," Clinical Orthopaedics and Related Research, no. 311, pp. 46-53, 1995.
[2] C. H. Rorabeck, R. B. Bourne, B. D. Mulliken et al., "The Nicolas Andry award: comparative results of cemented and cementless total hip arthroplasty," Clinical Orthopaedics and Related Research, no. 325, pp. 330-344, 1996.

[3] Y. T. Konttinen, J.-W. Xu, H. Pätiälä et al., "Cytokines in aseptic loosening of total hip replacement," Current Orthopaedics, vol. 11, no. 1, pp. 40-47, 1997.

[4] D. Bin and P. C. Noble, "Aseptic loosening of cemented stem following cemented hip arthroplasty: analysis of 36 revised specimens," Journal of Clinical Rehabilitative Tissue Engineering Research, vol. 13, no. 26, pp. 5176-5180, 2009.

[5] M. Jasty, W. J. Maloney, C. R. Bragdon, D. O. O'Connor, T. Haire, and W. H. Harris, "The initiation of failure in cemented femoral components of hip arthroplasties," Journal of Bone and Joint Surgery-Series B, vol. 73, no. 4, pp. 551-558, 1991.

[6] L.-F. Zhang, S.-R. Ge, H.-T. Liu, K.-J. Guo, S.-Y. Han, and J.-Y. Qi, "Bond strength analysis of the bone cement- stem interface of hip arthroplasties," Asian Pacific Journal of Tropical Medicine, vol. 7, no. 2, pp. 153-159, 2014.

[7] A. B. Lennon and P. J. Prendergast, "Evaluation of cement stresses in finite element analyses of cemented orthopaedic implants," Journal of Biomechanical Engineering, vol. 123, no. 6, pp. 623-628, 2001.

[8] S. B. Goodman, "The effects of micromotion and particulate materials on tissue differentiation: bone chamber studies in rabbits," Acta orthopaedica Scandinavica. Supplementum, vol. 65, no. 258, pp. 1-43, 1994.

[9] L. Ryd, "Roentgen stereophotogrammetric analysis of prosthetic fixation in the hip and knee joint," Clinical Orthopaedics and Related Research, no. 276, pp. 56-65, 1992.

[10] J. Kärrholm, B. Borssen, G. Lowenhielm, and F. Snorrason, "Does early micromotion of femoral stem prostheses matter? 4-7-year stereoradiographic follow-up of 84 cemented prostheses," Journal of Bone and Joint Surgery-Series B, vol. 76, no. 6, pp. 912-917, 1994.

[11] C. A. Engh, D. O’Connor, M. Jasty, T. F. McGovern, J. D. Bobyn, and W. H. Harris, "Quantification of implant micromotion, strain shielding, and bone resorption with porous-coated anatomic medullary locking femoral prostheses," Clinical Orthopaedics and Related Research, no. 285, pp. 13-29, 1992.

[12] M. Jasty, C. Bragdon, D. Burke, D. O'Connor, J. Lowenstein, and W. H. Harris, "In vivo skeletal responses to porous-surfaced implants subjected to small induced motions," Journal of Bone and Joint Surgery A, vol. 79, no. 5, pp. 707-714, 1997.

[13] X. Cai, J. Wang, and S. Lu, "Comparative study of PDGF-B and BMP-7 receptors distribution on histiocytes of interface membranes around aseptic loosened prostheses," Chinese Journal of Orthopaedics, vol. 6, no. 1, pp. 26-28, 2001.

[14] D. Nowell and D. Dini, "Stress gradient effects in fretting fatigue," Tribology International, vol. 36, no. 2, pp. 71-78, 2003.

[15] L. A. Blunt, H. Zhang, S. M. Barrans, X. Jiang, and L. T. Brown, "What results in fretting wear on polished femoral stems," Tribology International, vol. 42, no. 11-12, pp. 1605-1614, 2009.

[16] H. Zhang, L. Brown, L. Blunt, X. Jiang, and S. Barrans, "The contribution of the micropores in bone cement surface to generation of femoral stem wear in total hip replacement," Tribology International, vol. 44, no. 11, pp. 1476-1482, 2011.

[17] H. Y. Zhang, J. B. Luo, M. Zhou, Y. Zhang, and Y. L. Huang, "Biotribological properties at the stem-cement interface lubricated with different media," Journal of the Mechanical Behavior of Biomedical Materials, vol. 20, pp. 209-216, 2013. 
[18] H. Zhang, L. T. Brown, L. A. Blunt, X. Jiang, and S. M. Barrans, "Understanding initiation and propagation of fretting wear on the femoral stem in total hip replacement," Wear, vol. 266, no. 5-6, pp. 566-569, 2009.

[19] H. Y. Zhang, L. A. Blunt, X. Q. Jiang, L. T. Fleming, and S. M. Barrans, "The influence of bone cement type on production of fretting wear on the femoral stem surface: a preliminary study," Clinical Biomechanics, vol. 27, no. 7, pp. 666-672, 2012.

[20] J. Geringer, B. Forest, and P. Combrade, "Fretting-corrosion of materials used as orthopaedic implants," Wear, vol. 259, no. 7-12, pp. 943-951, 2005.

[21] J. Geringer, K. Kim, and B. Boyer, "14-Fretting corrosion in biomedical implants," in Tribocorrosion of Passive Metals and Coatings, D. Landolt and S. Mischler, Eds., pp. 401-423, Woodhead Publishing, 2011.

[22] J. Geringer, M. T. Mathew, M. A. Wimmer, and D. D. Macdonald, "2-Synergism effects during friction and fretting corrosion experiments-focusing on biomaterials used as orthopedic implants," in Biomaterials and Medical Tribology, J. P. Davim, Ed., pp. 133-180, Woodhead Publishing, 2013.

[23] J. Geringer, J. Pellier, F. Cleymand, and B. Forest, "Atomic force microscopy investigations on pits and debris related to frettingcorrosion between 316L SS and PMMA," Wear, vol. 292-293, pp. 207-217, 2012.

[24] J. Geringer, K. Kim, J. Pellier, and D. D. Macdonald, "Fretting corrosion processes and wear mechanisms in medical implants," in Bio-Tribocorrosion in Biomaterials and Medical Implants, Y. Yan, Ed., pp. 45-73, Woodhead Publishing, Cambridge, UK, 2013.

[25] K. Kim and J. Geringer, "Analysis of energy dissipation in fretting corrosion experiments with materials used as hip prosthesis," Wear, vol. 296, pp. 497-503, 2012.

[26] J. Pellier, J. Geringer, and B. Forest, "Fretting-corrosion between 316L SS and PMMA: influence of ionic strength, protein and electrochemical conditions on material wear. Application to orthopaedic implants," Wear, vol. 271, no. 9-10, pp. 1563-1571, 2011.

[27] B. R. Zhang, Z. B. Cai, X. Q. Gan, M. H. Zhu, and H. Y. Yu, "Dual motion fretting wear behaviors of titanium and its alloy in artificial saliva," Transactions of Nonferrous Metals Society of China, vol. 24, no. 1, pp. 100-107, 2014.

[28] M. Bryant, R. Farrar, K. Brummitt, R. Freeman, and A. Neville, "Fretting corrosion of fully cemented polished collarless tapered stems: the influence of PMMA bone cement," Wear, vol. 301, no. 1-2, pp. 290-299, 2013.

[29] J.-H. Yi, X.-Z. Lin, Z.-B. Cai, M.-X. Shen, L.-P. He, and M.H. Zhu, "Study on torsional fretting corrosion behaviors of Ti6Al4V alloy in the serum solution," Journal of Functional Materials, vol. 43, no. 7, pp. 919-923, 2012.

[30] L. Wu and D. Zhang, "Fretting wear study on the interface between titanium alloy ball and bone cement," Journal of Lubrication Engineering, vol. 36, no. 8, pp. 48-55, 2011.

[31] L. F. Zhang and S. R. Ge, "The effect of acrylic bone cement solidification conditions on the compressive property," Advanced Materials Research, vol. 197-198, pp. 1694-1699, 2011.

[32] J. S. Day, R. M. Baxter, M. L. Ramsey et al., "Characterization of wear debris in total elbow arthroplasty," Journal of Shoulder and Elbow Surgery, vol. 22, no. 7, pp. 924-931, 2013.

[33] J. R. Howell, L. A. Blunt, C. Doyle, R. M. Hooper, A. J. C. Lee, and R. S. M. Ling, "In vivo surface wear mechanisms of femoral components of cemented total hip arthroplasties : the influence of wear mechanism on clinical outcome," The Journal of Arthroplasty, vol. 19, no. 1, pp. 88-101, 2004.

[34] P. Sanz-Ruiz, E. Paz, J. Abenojar, J. Carlos del Real, J. Vaquero, and F. Forriol, "Effects of vancomycin, cefazolin and test conditions on the wear behavior of bone cement," Journal of Arthroplasty, vol. 29, no. 1, pp. 16-22, 2014.

[35] D. R. Sumner, H. Kienapfel, J. J. Jacobs, R. M. Urban, T. M. Turner, and J. O. Galante, "Bone ingrowth and wear debris in well-fixed cementless porous-coated tibial components removed from patients," The Journal of Arthroplasty, vol. 10, no. 2, pp. 157-167, 1995.

[36] V. Thomas, B. A. Halloran, N. Ambalavanan, S. A. Catledge, and Y. K. Vohra, "In vitro studies on the effect of particle size on macrophage responses to nanodiamond wear debris," Acta Biomaterialia, vol. 8, no. 5, pp. 1939-1947, 2012.

[37] R. L. Buly, M. H. Huo, E. Salvati, W. Brien, and M. Bansal, "Titanium wear debris in failed cemented total hip arthroplasty. An analysis of 71 cases," The Journal of Arthroplasty, vol. 7, no. 3, pp. 315-323, 1992.

[38] T. Jiao, Y. Wang, Q. Zhang, J. Zhou, and F. Gao, "Regulation of substituent groups on morphologies and self-assembly of organogels based on some azobenzene imide derivatives," Nanoscale Research Letters, vol. 8, article 160, 2013.

[39] T. Jiao, Q. Huang, Q. Zhang, D. Xiao, J. Zhou, and F. Gao, "Selfassembly of organogels via new luminol imide derivatives: diverse nanostructures and substituent chain effect," Nanoscale Research Letters, vol. 8, article 278, 2013. 

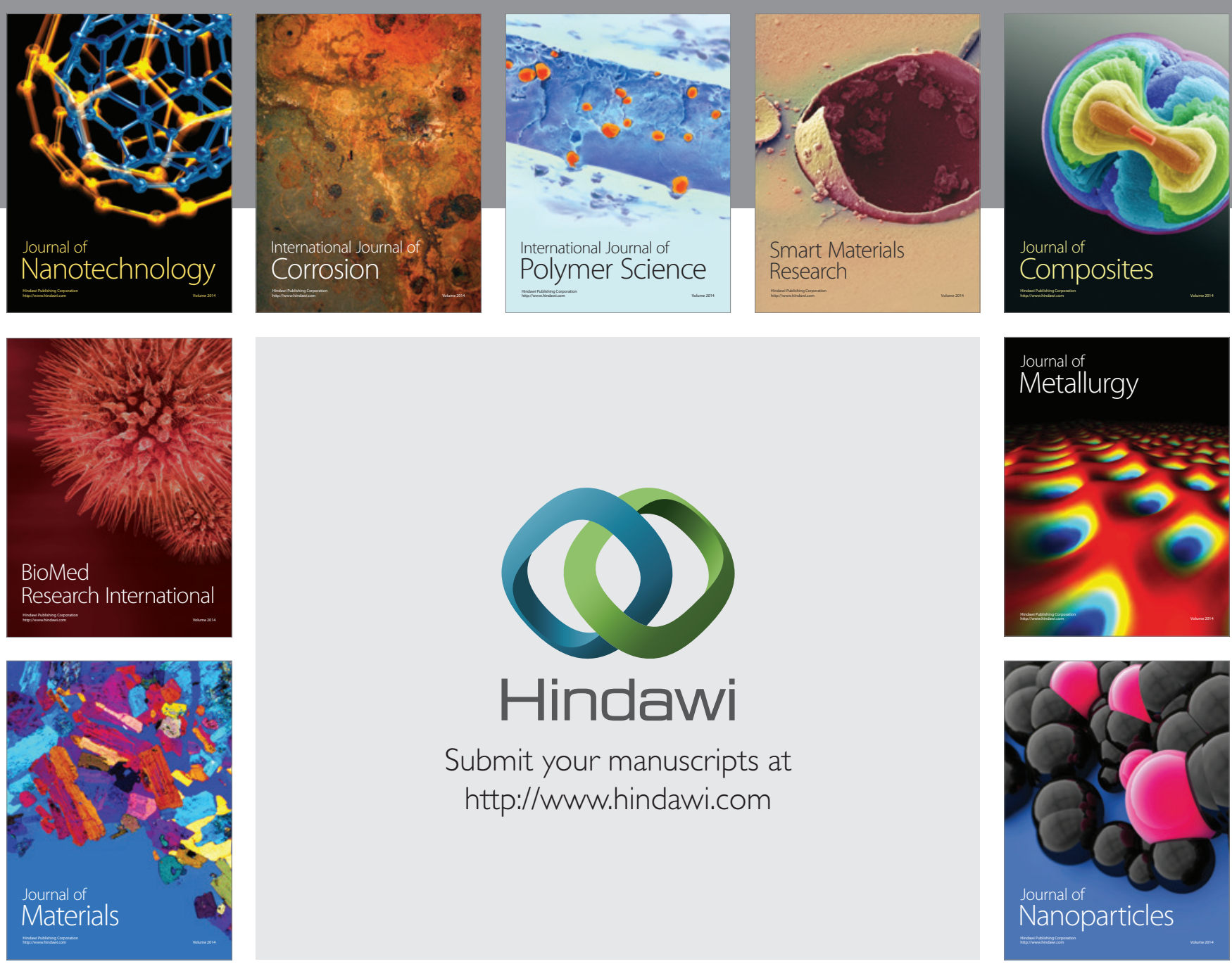

Submit your manuscripts at http://www.hindawi.com
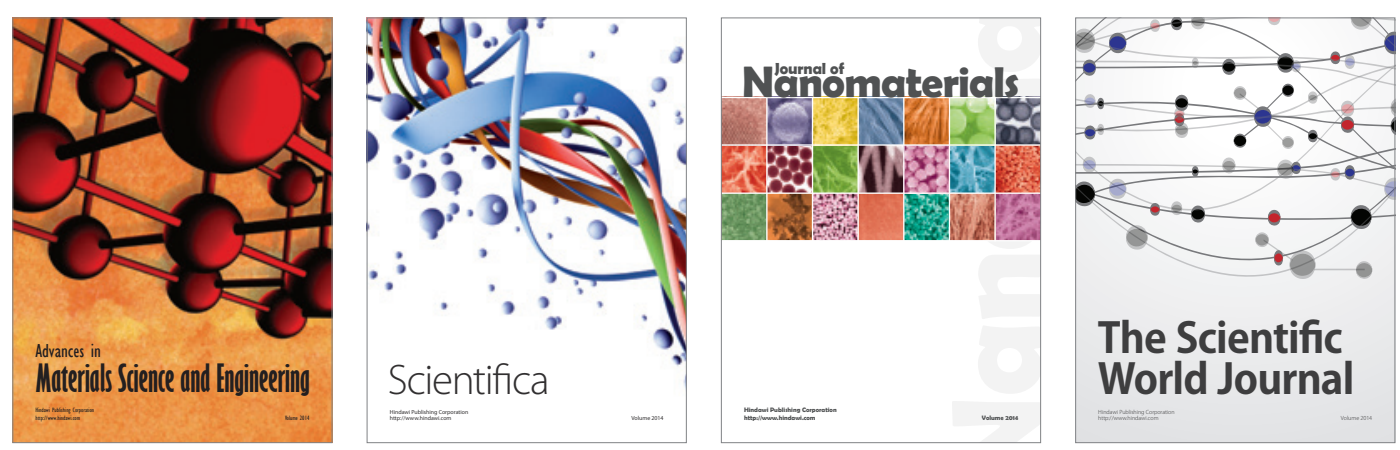

\section{The Scientific World Journal}
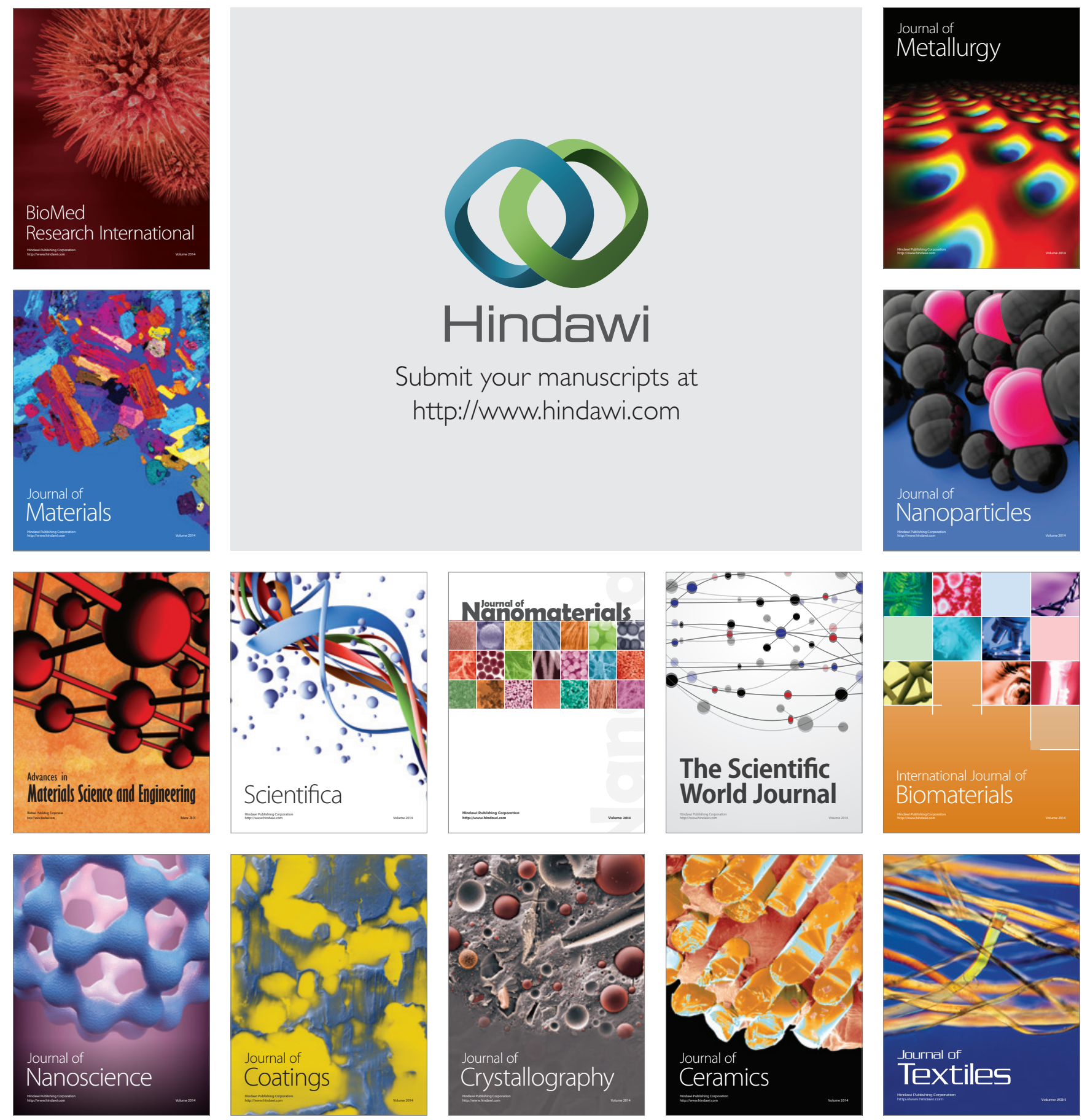